\section{RICYDE. Revista Internacional de Ciencias del Deporte doi: $10.5232 /$ ricyde \\ Rev. Int. cienc. deporte}

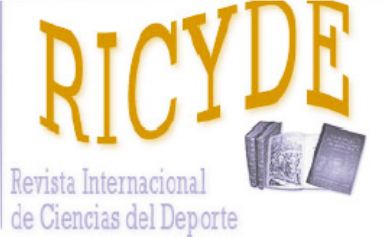

RICYDE. Revista Internacional de Ciencias del Deporte Volume XV - Year XV

Pages: 266-279 - ISSN: $1885-3137$ Issue 57 - July 2019

\title{
Explicit and implicit motor sequence learning: motor learning analysis in children with Down syndrome \\ Aprendizaje explícito e implícito de la secuencia motora: análisis del aprendizaje motor en niños con síndrome de Down
}

\section{Sayed Kavos Salehi ${ }^{1}$, Fatema Sadat Talebrokni ${ }^{2}$, Negar Miri-Lavasani ${ }^{3}$, Alborz Hajipour ${ }^{2}$}

1. Department of Motor Behavior, Faculty of Physical Education and Sport Sciences, Shahid Rajaee Teacher Training University, Lavizan, Tehran, Iran

2. Department of Motor Behavior, Faculty of Physical Education and Sport Sciences, University of Tehran, Kargar Street, Tehran, Iran

3. Department of Health and Social Development, Deakin University, Australia

\section{Abstract}

The purpose of the present study was to explore explicit and implicit motor sequence learning in 24 children with Down's syndrome (DS) and 24 matched typically developing (TD) children using a serial reaction time (SRT) task with both random and regular trials. The intervention was consisted of 10 stages ( 8 blocks for acquisition and 2 blocks for retention) in which the performances of groups were compared. In acquisition phase, our results showed a progress in the performance of SRT task in all groups while performing the SRT task. In addition, in retention phase, the results showed that children with DS succeed as well as TD children at the implicit motor sequence learning task. There were no significant differences between groups. But there was a significant difference between groups for explicit learning and the group of TD explicit children showed a reliable sequence learning pattern compared to DS children. These results are in line with the cognitive and motor features of the DS children and suggest that implicit motor learning is intact in children with DS but explicit motor learning seems to be impaired in these children. Nevertheless, this article provides preliminary data regarding implicit learning in DS children and further empirical research is needed to provide more meticulous and logical explanations. From a practical view, we suggest that during the education and rehabilitation interventions to children with DS, we can make use the benefits of implicit learning, because these children can learn skills implicitly.

Key words: Down syndrome; Serial reaction time task; Implicit and explicit motor learning; Motor sequence.

\section{Resumen}

El propósito del presente estudio fue explorar el aprendizaje de secuencias motoras explícitas e implícitas en 24 niños con síndrome de Down (DS) y 24 niños con un desarrollo típico (TD) pareados utilizando una tarea de tiempo de reacción en serie (SRT) con ensayos aleatorios y regulares. La intervención consistió en 10 etapas (8 bloques para adquisición y 2 bloques para retención) en las que se compararon los rendimientos de los grupos. En la fase de adquisición, nuestros resultados mostraron un progreso en el desempeño de la tarea SRT en todos los grupos al realizar la tarea SRT. Además, en la fase de retención, los resultados mostraron que los niños con SD tienen éxito, así como los niños con TD en la tarea de aprendizaje de la secuencia motora implícita. No hubo diferencias significativas entre los grupos. Pero hubo una diferencia significativa entre los grupos para el aprendizaje explícito y el grupo de niños explícitos con TD mostró un patrón de aprendizaje de secuencia confiable en comparación con los niños con SD. Estos resultados están en línea con las características cognitivas y motoras de los niños con SD y sugieren que el aprendizaje motor implícito está intacto en los niños con SD, pero el aprendizaje motor explícito parece estar afectado en estos niños. Sin embargo, este artículo proporciona datos preliminares sobre el aprendizaje implícito en niños con SD y se necesita más investigación empírica para proporcionar explicaciones más meticulosas y lógicas. Desde un punto de vista práctico, sugerimos que durante las intervenciones de educación y rehabilitación para niños con SD, podamos aprovechar los beneficios del aprendizaje implícito, porque estos niños pueden aprender habilidades de manera implícita.

Palabras clave: síndrome de Down; tarea de tiempo de reacción en serie; aprendizaje motor implícito y explícito; secuencia motora.

Correspondencia/correspondence: Sayed Kavos Salehi

Department of Motor Behavior, Faculty of Physical Education and Sport Sciences, Shahid Rajaee Teacher Training University, Lavizan, Tehran, Iran Email: Sk.salehi@yahoo.com 
Salehi, S. K.; Talebrokni, F. S.; Miri-Lavasani, N., \& Hajipour, A. (2018). Explicit and implicit motor sequence learning: motor learning analysis in children with Down syndrome. RICYDE. Revista internacional de ciencias del deporte. 57(15), 266-279. https://doi.org/10.5232/ricyde2019.05705

\section{Introduction}

$\mathrm{D}$ own syndrome (DS), also known as tiresome 21 , is one of a genetic disorder that affects motor development and learning. It caused by the presence of an extra chromosome in the 21 st pair of chromosomes; thus, the zygote has 47 chromosomes instead of the normal 46 chromosomes. Within the United States, approximately 1 in 700 infants is born with DS each year, making it a prevalent genetic disorder (National Down Syndrome Society, 2017). Infants born with DS, will have a variety of physical problems and often experience intellectual disabilities (Bittles, Bower, Hussain, \& Glasson, 2007). DS considered the most common organic form of mental retardation (Weeks, Chua, \& Elliott, 2000). The cognitive profile of individuals with DS is characterized by a clear deficit in language ability, especially in morphsyntax (e.g. Fowler, 1995), while visuospatial short-term memory appears relatively preserved (e.g. Hick, Botting, \& Conti-Ramsden, 2005). The linguistic deficit seems more pronounced in production than in comprehension (Vicari, 2006; Vinter \& Detable, 2008). In general, there is no cure for Down syndrome, but understanding the physical, mental, perceptual-motor, developmental aspects of people with Down syndrome, education and proper care have been shown to improve quality of life (Roizen \& Patterson, 2003; Deborah, Fidler, \& Nadel, 2007). One of the consequences of this syndrome that its analysis can have practical implications to improve quality of life and adaptation to the environment in the affected population is motor learning difficulties (Chiviacowsky, Machado, Marques, Schild, Drews, 2013).

Motor learning refers to a set of processes associated with practice and experience leading to relatively permanent changes in motor performance (Maas, Robin, Hula, Freedman, Wulf, Ballard, Schmidt, 2008). It is suggested that two types of learning processes occur simultaneously during the acquisition of a functional motor skill: explicit learning and implicit learning processes (Gentile, 1998; Salehi, Sheikh, Hemayattalab, Humaneyan, 2016). Informing the participant about the goal and execution of motor task in a way that learner can explain it verbally is believed to be explicit motor learning (Robertson, 2007; Taylor \& Ivry, 2013). Contrary to explicit learning, the implicit motor learning process is the process by which knowledge about the rule-governed complexities of the stimulus environment is acquired independently of conscious attempts to do so. Implicit motor learning results when the learner (for example, children) are unaware of movement components (Robertson, 2007). Motor learning implicitly is characterized by a lack of awareness for the learning process and its content (Reber, 1993; Izadi-Najafabadi, Mirzakhani-Araghi, Miri-Lavasani, Nejati, \& Pashazadeh-Azari, 2015).

Implicit and explicit motor learning have fundamental differences in encoding and retrieval mechanisms and are controlled by different neural networks. It is believed the neural network that controls the implicit learning include the basal ganglia, cerebellum and prefrontal cortex, while explicit learning is controlled by temporal lobe, hippocampus, thalamus, and prefrontal parietal cortex (Thomas \& Nelson, 2001). These are interdependent processes that might change at different rates and levels for different motor functions. Moreover, treatment methods are typically different according to each of these two learning processes (Gentile, 1998).

Early theories of implicit learning postulated that because implicit learning is a fundamental, adaptive cognitive mechanism, it should recruit evolutionarily basic brain regions, demonstrate early maturation and is development invariant. In this case, Reber (1993), proposed the developmental invariance model. According to this model, implicit learning is independent from age, because neural structures involved in implicit learning are evolutionarily more primitive and very soon grow and develop so that during childhood remain relatively the same and without altering, while explicit learning show more developmental changes during the time, because this type of learning involves more cortical structures which continue to develop across childhood and into adolescence (Meulemans, Van der Linden, \& Perruchet, 1998; Karatekin, Marcus, \& White, 2007). By contrast to this view, age-related changes model in implicit 
Salehi, S. K.; Talebrokni, F. S.; Miri-Lavasani, N., \& Hajipour, A. (2018). Explicit and implicit motor sequence learning: motor learning analysis in children with Down syndrome. RICYDE. Revista internacional de ciencias del deporte. 57(15), 266-279. https://doi.org/10.5232/ricyde2019.05705

learning is presented. The age-related changes models posit that considerable developmental differences can be observed in implicit learning. A growing body of these studies found that older children and young adults showed stronger learning effects compared to very young participants (Maybery, Taylor, \& O’Brien-Malone., 1995; Fletcher, Maybery, \& Bennett, 2000; Thomas, Vizueta, Sommer, Durston, Yang, Worden., 2004; Kirkham, Slemmer, Richardson, \& Johnson, 2007; Janacsek, Fiser, \& Nemeth., 2012).

Some believe that implicit learning is not dependent on IQ, but explicit learning is related to IQ; that means if explicit learning occurs in the process of an implicit task, the low IQ can indicate a defect in implicit learning (Reber, Walkenfeld, \& Hernstadt, 1991). Based on this idea, the implicit learning tasks may be damage in the conditions in which IQ is usually depressed relative to neurotypicals, including Down's syndrome, autism spectrum disorders, mental retardation and intellectual impairment (Atwell, Connors \& Merrill., 2003; Vicari, Verruci, \& Carlesimo, 2007; Vinter \& Detable, 2008; Brown, Aczel, Jimenez \& Kaufman, 2010; Bussy, Charrin, Brun, Curie \& des Portes., 2011). For example. Some studies have reported results that children with specific language impairment, also developmental coordination disorder are able to learn a new implicit task as quickly and accurately as children without any developmental disorder (e.g., Gabriel, Maillart, Guillaume, Stefaniak, \& Meulemans, 2012; Lejeune, Catale, Willems, Meulemans, 2013) These findings suggest that perhaps implicit learning is indeed IQ-independent, and may be intact in people with Down's syndrome disorder. This is an area of interest that has been addressed in this study.

Mostly, the typical behavior that is used to evaluate the functions of implicit and explicit learning is motor sequence learning, as motor sequence could be learnt explicitly or implicitly. In 'Explicit Motor Sequence Learning' learning the learner is aware from arrangement of sequence but in implicit one is unaware (Robertson, 2007). 'Serial Reaction Time Task (SRTT)' is an experimental paradigm frequently used to explore and study both implicit and explicit motor sequence learning. It is a method that a sequence of visuo-spatial signals guides subjects to perform a sequence of movements which follow a frequently pattern (Nissen \& Bullemer, 1987). SRT contains motor and cognitive components and requires motor responses to visual stimuli (colors) appearing in a patterned or random sequence. Sequence repetition speeds up responses to stimuli by decreasing time needed to make proper response. This decrement is seen in both patterned and random sequences. Changes in duration of patterned sequences imply learning speed. Error making decrement in responding to stimuli (learning accuracy) is another criterion of leaning (Izadi-Najafabadi, Mirzakhani-Araghi, Miri-Lavasani, Nejati, \& Pashazadeh-Azari, 2015).

Some studies have shown the advantage and transcendence of implicit learning when comparing explicit and implicit learning and this is especially major when the structure of the task is complex. Reber (1976) showed that, in an artificial grammar learning task, participants who engaged in an explicit process of rule discovery performed worse than participants who learned incidentally. However, contradictory results have again been published in the literature (e.g. Dienes, Broadbent, \& Berry, 1991; Dulany, Carlson, \& Dewey, 1984). To our knowledge, only two studies have compared these two types of learning in individual with intellectual impairment. First, Atwell, Conners \& Merrill (2003) using an artificial grammar learning paradigm, compared the effect of both types of learning in young adults with IQs varying from 50 to 75 , and with intellectual impairment caused by mixed aetiologies. For some participants, sequences were constructed following an artificial grammar; for others, sequences were random. Explicit learning was determined by ability to learn and later identify random sequences. Implicit learning was determined by the tendency to incorrectly identify new grammatical sequences as seen before, relative to new nongrammatical sequences. Results indicated that participants with mental retardation did more poorly than participants without mental retardation on explicit learning but just as well on implicit learning. These results similar 
Salehi, S. K.; Talebrokni, F. S.; Miri-Lavasani, N., \& Hajipour, A. (2018). Explicit and implicit motor sequence learning: motor learning analysis in children with Down syndrome. RICYDE. Revista internacional de ciencias del deporte. 57(15), 266-279. https://doi.org/10.5232/ricyde2019.05705

with Reber (1976) suggests the superiority of implicit learning than explicit. Not so long ago, Vinter \& Detable (2008) used the graphical implicit learning task to compare implicit and explicit performance in children with or without Down's syndrome with IQs varying across a wider range, from 30 to 70, and single specific aetiology. The implicit learning task was based on the manipulation of a graphic production principle. Participants trained to reverse the principle. In the explicit task, participants had to learn the two rules that account for this reversed principle. Their results showed that Children with DS performed as well as controls in the implicit learning condition. They benefited less from the explicit learning condition than controls. Besides, they appeared to be impaired in the ability to recollect explicit information about the implicit training situation in comparison with controls. These contradictory, limited findings and lack of consistency between researches highlight the need and necessity for further research in this practical area.

It can be expected that implicit learning in Downs's syndrome be more because of their specific cognitive functions, include overly compliant approach to tasks, and their strong tendency to rely on imitation (Rast \& Meltzoff, 1995; Wright, Lewis, \& Collis, 2006). These features make them to shape their behavior in accordance with the structure of the encountered situations. The predominance of such 'empirical' functioning may make them particularly sensitive to the incidental conditions of learning and to the action of automatic associative processes that are thought to capture structural regularities present in the learning situation (Perruchet, Vinter, Pacteau, \& Gallego, 2002; Vinter \& Detable, 2008). By contrast, their difficulties when effortful or intentional processing is required are regularly reported (e.g. Cuskelly, Jobling, \& Buckley, 2002). In fact, Implicit function is thought to involve a slower learning system in which encoding can be incidental or unintentional, and retrieval occurs outside of conscious awareness or deliberation (Tulving \& Schacter, 1990; Tomas \& Nelson, 2001). This type of learning tends to result in knowledge that is more tightly bound to the particular features of the learning context (Reber, 1993; Schacter, 1992). In contrast, Explicit functions appear to be supported by a fast learning system that is particularly useful for episodic encoding from a single instance. The knowledge acquired is declarative in that the learner can verbally explicate the learned information, it can be manipulated by conscious strategy use, and it is relatively flexible, allowing transfer of learning to new yet analogous settings (Eichenbaum, Matthew, \& Cohen, 1989; Tomas \& Nelson, 2001).

In this context, the aim of our study was to more thoroughly explore explicit and implicit motor sequence learning in children with and without Down's syndrome by means of the SRT task. In this task, participants are asked to responsd to the specific stimuli as quickly as possible by pressing a buttons that corresponds to the location of the stimuli. Stimuli were presented sequentially and participants' response times were recorded. Unknown to the participants, the order of the presented stimuli was switched between series of random (irregular) and fixed (regular) sequence positions. Under the circumstances, in which the participants remained unaware of such regular order, the decreasing in response times to stimuli in a regular as compared to irregular order represented implicit sequence knowledge. Since stimuli were grouped in large sets, called blocks, the indicator of implicit sequence knowledge was the difference in main response times between the final sequence block and the subsequent random block (Sweeney, Rosano, Berman \& Luna., 2001; Nejati, Garusi Farshi, Ashayeri \& Aghdasi., 2008). This study is unique and distinctive in that we use a version of SRT that alternates between repeating and random events. SRT task is a kind of fine perceptual - motor task. Given the fact that the issue of fine movements and hand skills is one of the key concepts in the rehabilitation and occupational therapy of Down syndrome individuals and their performance could be improved. Therefore, it seems that the SRT task measures precisely the motor performance of these individuals. One advantages of this type over classic SRT is its ability to hide the sequence and track the sequence-specific learning. The possibility of using explicit strategies during implicit motor learning is reduced to its most by setting response- to-stimulus 
Salehi, S. K.; Talebrokni, F. S.; Miri-Lavasani, N., \& Hajipour, A. (2018). Explicit and implicit motor sequence learning: motor learning analysis in children with Down syndrome. RICYDE. Revista internacional de ciencias del deporte. 57(15), 266-279. https://doi.org/10.5232/ricyde2019.05705

interval (SRI) at 0 and using random blocks. Moreover, to the best of our knowledge, this is one of the few studies to assess both implicit and explicit motor learning using the same task which makes it possible to compare these two types of learning with highly accurate and without any human error in data recording. The results of this study are applied to the motor learning inherent in the occupational and physical performance approach for children with DS.

\section{Method}

\section{Participants}

Forty-eight right-handed children aged 6-12 years (24 DS and 24 typically developing (TD) children matched based on chronological age, gender, and mental age) participated in the study. Each group was divided into two equal groups of implicit and explicit motor learning. Group characteristics are shown in Table 1.

The children with DS met with the criteria for the diagnosis of mental retardation based on the Diagnostic and Statistical Manual of Mental Disorders (DSM-IV) (American Psychiatric Association, 1994) and had IQs between 60 and 70 percent. They were selected from schools for special education and rehabilitation centers in Masjedsolyman (Khuzestan, Iran). Teachers or physiotherapists were asked to identify children who met the following criteria: children between 6 and 12 years old, having marked motor deficits caused by Down syndrome, an IQ score between 60 and 70 percent, no diagnosed behavioral disorder such as ADHD or autism and no language disorder or severe sensory, motor impairments.

Table 1. Characteristic participant groups

\begin{tabular}{|l|c|c|l|l|l|l|c|c|}
\hline \multirow{2}{*}{} & \multirow{2}{*}{} & $\mathrm{N}$ & Gender & \multicolumn{2}{|c|}{ CA age } & \multicolumn{2}{c|}{ MA age } & \multicolumn{2}{c|}{ IQ performance } \\
\cline { 3 - 9 } & & Boy / Girls & M (SD) & Range & M (SD) & Range & M (SD) & Range \\
\hline DS / explicit & 12 & $6 / 6$ & $10.7(1.56)$ & $6-12$ & $5.5(1.3)$ & $5.1-8.3$ & $64.8(6.1)$ & $60-70$ \\
\hline DS / implicit & 12 & $6 / 6$ & $11.3(1.51)$ & $5-12$ & $5.5(1.1)$ & $5.2-8.6$ & $65.1(5.85)$ & $60-70$ \\
\hline TD / explicit & 12 & $6 / 6$ & $5.1(1.62)$ & $5-12$ & $5.0(0.7)$ & $5.4-9.1$ & $68.8(5.47)$ & $60-70$ \\
\hline TD / implicit & 12 & $6 / 6$ & $5.0(1.54)$ & $5-12$ & $5.0(0.8)$ & $5.2-8.7$ & $68.3(5.38)$ & $60-70$ \\
\hline
\end{tabular}

All participants were tested individually, on the Raven's Coloured Progressive Matrices test to assess and matching IQs of participants (Raven, Court \& Raven., 1990). This test is designed to measure the individual's ability to create perceptual relationships, language independent deductive reasoning and non-verbal performance. Throughout the task, participants must indicate which of six pieces fits into a target gap to correctly complete a visual pattern. Depending on whether the answer is correct or false, a score of one or zero is awarded to the subject. The IQ of between $50 \%$ and $70 \%$ indicates mental retardation. In the current study, children who did not receive IQ of 60 and $70 \%$ ( 5 people because of an IQ score $<50 \%$ ) were excluded from the study. 48 subjects who had required criteria were selected and after matching based on IQ, chronological and mental age, were divided into four groups. Mean of chronological age and mental age were similar in implicit and explicit groups. Moreover, All participants were right-handers using Hand Edinburg Inventory (Oldfield, 1971). No participants had experienced visual and auditory impairment, motor dysfunction in upper limb, secondary physical or sensory disease, or seizure based on their parents' report or medical records. The study was approved by the local ethical committee and written informed consent was obtained from the parents before testing. 
Salehi, S. K.; Talebrokni, F. S.; Miri-Lavasani, N., \& Hajipour, A. (2018). Explicit and implicit motor sequence learning: motor learning analysis in children with Down syndrome. RICYDE. Revista internacional de ciencias del deporte. 57(15), 266-279. https://doi.org/10.5232/ricyde2019.05705

\section{Instrument}

\section{Serial Reaction Time (SRT) task}

A version of the SRT task (Nissen \& Bullemer, 1987) was administered on a portable laptop. SRT task involving a the four colored squares (yellow, green, blue, and red), displaying on monitor as stimulus, and participants were asked to press the corresponding button on the keyboard with their index finger of their right hand as quickly and accurately as possible. Corresponding keys on keyboard were defined as response keys for stimuli. For example, "right Shift" for green, " $M$ " for red, "V" for yellow, and "left Shift" for blue color. Computer software of SRT recorded all results, time (ms) and error (number), for each participant.

Each participant performed 10 blocks of sequences. Each block contained 10 trials (sequences). Each trial contained eight stimuli which appeared sequentially. Thus providing stimuli in regular sequence included green, blue, yellow, blue, red, yellow, green, yellow and in irregular sequence, stimuli are presented in a random order, which means that the provision of stimuli is determined by software and there is no logical relationship in the order of their appearance. All blocks followed this regular sequence except the three and the sixth which had irregular or random sequences in order to diminish the possibility of explicit strategy use in implicit groups.

\section{Procedure}

Participants were tested separately in a quiet environment and seated comfortably on a chair in front of monitor of a laptop. First, they were informed about the task demands and the procedure of the experiment. The testing session lasted approximately 30-40 min. Participants were allowed to take breaks between blocks from 1 to $15 \mathrm{~min}$ as needed. The intervention involves 10 stages in two phases (acquisition and retention) in which the results of the groups were compared. Participants first entered the acquisition phase. This phase consists of 8 blocks (each block consists of 10 trials and each trial includes 8 stimulation) that the appearance of the squares in all blocks except blocks 3 and 6 was regular order. Therefore, in this study the mixed motor sequences (the combination of repetitive regular and irregular) were used, because the possibility of explicit knowledge in implicit learning groups become minimized.

In the process of research, carrying out experiments was exactly the same in implicit and explicit learning groups, except that before the test, explicit learning groups (DS and TD children) receive complete information about the emergence of squares and sequence them, using the following procedure. Prior to starting each set, stimuli order was drawn on a piece of paper and presented to children in the explicit learning group to get the knowledge of patterned sequences. They were told to follow the order. The drawing was available to them throughout the task to check the order if needed. They were also told to press the corresponding button as quickly and as accurately as they could, but participants in implicit learning groups (both children with DS and their matched TD peers) were not given any information and were not aware of the sequences, Just they were asked which immediately after observing any square, press the corresponding button as quickly and as accurately as they could. It should be noted that prior to practice on the SRT, a block for Familiarization phase was performed by different subjects. To examine children's awareness of the patterned sequence in the implicit motor learning groups, they were asked whether they noticed anything while performing the task. If any, they were asked to verbally state it.

One day (24 hours) after the acquisition phase, the second phase; the measurement of learning retention was performed. This phase consists of 2 blocks with the same regular arrangement of the first phase. 
Salehi, S. K.; Talebrokni, F. S.; Miri-Lavasani, N., \& Hajipour, A. (2018). Explicit and implicit motor sequence learning: motor learning analysis in children with Down syndrome. RICYDE. Revista internacional de ciencias del deporte. 57(15), 266-279. https://doi.org/10.5232/ricyde2019.05705

The reaction time, errors in response were recorded by A DELL laptop (Windows XP). The performance of participants in explicit and implicit sequence learning was monitored by a decrease in reaction time, errors in response by calculating the percentage of correct key presses made for each stimulation, trial and block.

\section{Statistical methods}

An alpha level of 0.05 was used for all statistical analyses. The data were analyzed with repeated measures analyses of variance (ANOVAs; Greenhouse - Geisser corrections are reported when sphericity was violated), with Group as the between-subject factor and sequence type, block and learning condition as the within-subject factors. Significant main effects and interactions were analyzed using pairwise comparisons, with Bonferroni adjustment for multiple comparisons. The accuracy is not considered as a factor of motor learning in this study because accuracy scores during the SRT task were very high in all groups $(95 \%$ per block, $\mathrm{SD}=3.21)$. The difference between groups was not significant, $\mathrm{t}(27)=-0.68, p=0.121$, showing that children with DS did not make more errors than TD children. Because these accuracy scores were very high, they were not analyzed further.

\section{Results}

\section{Acquisition phase}

The results for reaction time (Fig. 1) during the acquisition phase ( 8 blocks) showed that there was a significant main effect of block $\mathrm{F}(1.23,78.19)=3.66, p<0.05$, such that there were significant improvements in performance across all blocks of practice $(p \leq 0.001)$. There was also a significant main effect of Sequence Type $F(1,67)=4.345, p<0.05$ was found, indicating that key press responses in the regular sequences was performed faster than the random sequences in all groups. Also, there was a significant main effect of group F $(2.95)=0.654$, such that explicit groups were performed significantly faster than implicit groups. Post hoc planned comparisons revealed that TD explicit and implicit groups performed significantly faster than other groups $(p<0.05)$. Lastly, there was a significant Block $\times$ Group interaction $F$ $(4.32,79.68)=2.321, p=0.013$, such that overall TD explicit and implicit groups were significantly faster than DS explicit and implicit groups on all blocks $(p \leq 0.001)$. At this stage not found significant effects for interaction between other variables $(p \geq 0.05)$. In general, typical children sped up during explicit SRT task and post hoc analyses revealed that there were significant differences between the eighth and second blocks in all groups $(p<0.05)$, which represents the improvements in performance. Between groups differences showed that response time for explicit groups in all blocks was significantly faster than implicit groups $(p<0.05)$. In addition, TD groups were marginally faster than the DS one $(p<0.05)$. Neither the children with DS nor the TD children in implicit motor learning group were able to verbally and explicitly state the sequence and the response to the stimuli was implicitly.

In the acquisition phase, the results showed that general implicit motor learning occurs in children with DS which might be a sign of intact implicit learning in these children. The reaction times for each block was presented in Fig. 1

\section{Retention phase}

When comparing response time for the groups across the 2 last blocks of practice on Day 2 (late-learning) and the 2 first blocks on Day 1 in retention phase, the results indicated overall retention in studied groups, such that there were significant improvements across the two last blocks ( 9 and 10 compared to 1 and 2 ) of practice $\mathrm{F}(1.54)=345.34, \mathrm{P}=0.005$. There was also a significant main effect of group F $(2.78)=396.78, p<0.05$, revealed that TD children were marginally faster than the DS children and explicit groups were performed significantly faster than implicit one $(p<0.05)$. 
Salehi, S. K.; Talebrokni, F. S.; Miri-Lavasani, N., \& Hajipour, A. (2018). Explicit and implicit motor sequence learning: motor learning analysis in children with Down syndrome. RICYDE. Revista internacional de ciencias del deporte. 57(15), 266-279. https://doi.org/10.5232/ricyde2019.05705

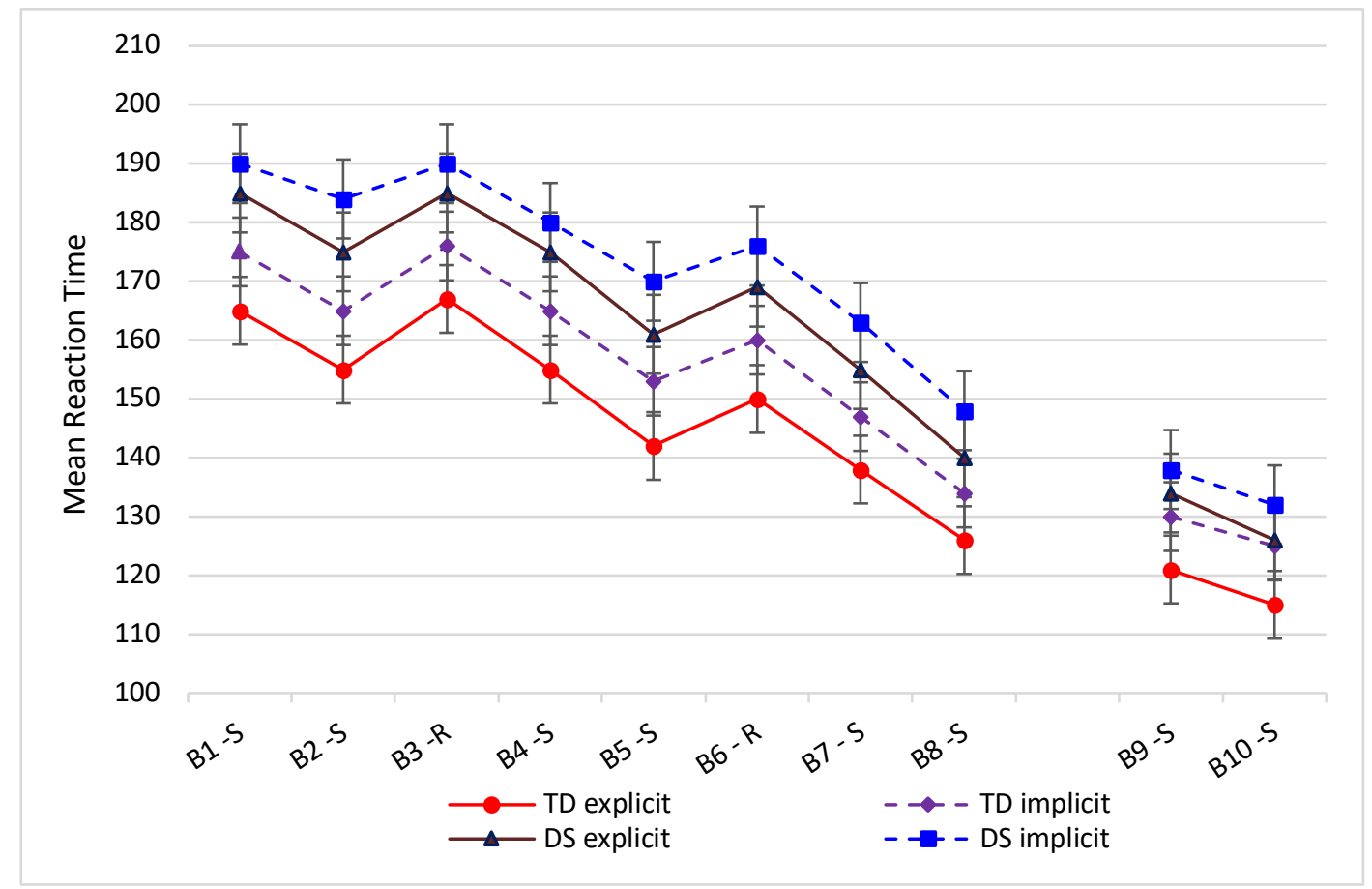

Fig 1. Mean of the reaction times in each block for the DS and the TD groups. B, block; S, sequence or regular; $\mathrm{R}$, random

For explicit motor learning, group comparison indicated differences between children with DS and TD peers suggesting explicit learning deficit in children with DS $(\mathrm{F}(2,63)=5.28, p<$ 0.05). Thus, although the current analysis shows signs of specific explicit motor learning in children with DS, their significant difference with the TD group is an indicative of deficit.

For implicit motor learning, group comparison shows no difference between children with DS and TD which suggest an intact implicit motor learning in children with DS and that these two groups are similar in this type of learning.

To assess the association between an overall measure of performance on the SRT task and neuropsychological measures administered, two-tailed Pearson correlations were performed by group. Overall, no significant correlations were found between overall performance on the SRT task and the Raven's Colored Progressive Matrices Intelligence test $(p>0.05)$.

\section{Discussion}

The purpose of the present study was to examine explicit and implicit motor sequence learning in children with Down syndrome and their typically developing counterparts. In the current study, we chose to employ the same task for all groups, in order to compare group differences across a common paradigm. Overall, our results showed a progress in the performance of SRT task. The time difference in eighth and second blocks was significant, indicating improvement of speed in all groups while performing the SRT task. This means that practice and repeatedly response to serial stimuli resulted in, the speed of reaction to stimuli and improved in both repetitive and random sequences. However, reaction time in random sequences was more than a regular sequences, indicating that implicit learners responded to stimuli without the knowledge conscious about the order of sequences. This finding is consistent with the findings of Atwell, Conners \& Merrill (2003) and shows the role of practice in improving the performance and learning. In addition, Specific learning in retention phase, however, differed between groups: overall, the group of TD explicit children showed a reliable sequence learning pattern compared to DS children, whereas there was no difference between children with DS 
Salehi, S. K.; Talebrokni, F. S.; Miri-Lavasani, N., \& Hajipour, A. (2018). Explicit and implicit motor sequence learning: motor learning analysis in children with Down syndrome. RICYDE. Revista internacional de ciencias del deporte. 57(15), 266-279. https://doi.org/10.5232/ricyde2019.05705

and TD in implicit learning which suggest an intact implicit motor learning in children with DS and that these two groups are similar in this type of learning. These results are in line with studies, which have indicated that motor skill learning is still intact in children with some mental impairments but the rate of learning is somewhat slower and are consistent with Vinter \& Detable, 2008, and Izadi-Najafabadi, Mirzakhani-Araghi, Miri-Lavasani, Nejati, \& Pashazadeh-Azari, 2015. However, the results of our research are somewhat different from those of the Vinter \& Detable, 2008, because in the study of Vinter \& Detable, 2008, the implicit learning of DS children was superior to the explicit learning of them, but in our research there was no significant difference between these two types of learning. The reason for this difference is probably related to methodological limitations such as task used in the experiments. The SRT task used in our research is fundamentally different from the graphical implicit learning task, which be caused different results.

Our results suggest that children with DS learned the SRT task implicitly at about the same rate as the TD children. However, the DS children remained slower than their peers at the explicit learning at every stage, and the performance level that they reached was lower than that of the TD children; in other words, the difficulties observed at the outset did not diminish with practice. Slow performance on motor tasks has often been reported in children with learning difficulties such as developmental coordination disorder and Down's syndrome. Indeed, several studies have found that children with learning difficulties perform a motor task significantly more slowly than controls (e.g., Vicari, Bellucci \& Carlesimo., 2000; Atwell, Conners \& Merrill., 2003). In SRT tasks, explicit learning occurs when people recognize a sequential task, which activates the fronto -parietal network in both cerebral hemispheres. Therefore, during explicit learning using one hand, there is a hemisphere map of the same side. The relationship between the two hemispheres for performing a visual-motor task is done at the initial stages of explicit learning through the prefrontal cortex to create a relationship between visual and motor commands during the performing of the task with right hand. It has also been shown that in the initial stages of explicit learning, increased activity is observed in the right parietal lobe, which can be due to spatial attention or the need to convert visual information into spatial or motor information during perceptual- motor task learning. It is believed that in explicit learning, due to the activation of working memory and the increasing demand for attention, there is a great deal of ability to perform mental processes and to memorize the components of movement. Therefore, the short-term memory weakness and consequently working memory in children with DS can be the reason for some of the deficiencies especially in the context of explicit learning. In addition, based on our results, implicit learning and explicit learning in DS children had similar results and did not differ between them. However, an examination of mean and standard deviations values showed that in these children the mean of explicit learning language was upper than that of implicit learning. This result is in agreement with the results of the Klinger and Dawson, 2001, which showed that participants with DS in explicit learning rule formation conditions had better performance than implicit learning condition. And contradicts with some of the research results of Vinter \& Detable, 2008. Because their research results showed a greater impact of implicit learning than explicit learning in children with DS. The reason for this discrepancy and no significant difference between the two types of learning in the present study, the superiority of implicit learning on explicit learning in the research of Vinter \& Detable, 2008 and the superiority of explicit learning on implicit learning in the research of Klinger and Dawson, 2001 perhaps related to the type and complexity of the task was used in various research. The task used in current study was simple. Research has shown that an advantage of implicit learning on explicit learning occurs especially when the rules in the task are complex. Because if the task be too complex, explicit rules will make it more difficult for children with DS. 
Salehi, S. K.; Talebrokni, F. S.; Miri-Lavasani, N., \& Hajipour, A. (2018). Explicit and implicit motor sequence learning: motor learning analysis in children with Down syndrome. RICYDE. Revista internacional de ciencias del deporte. 57(15), 266-279. https://doi.org/10.5232/ricyde2019.05705

According to our results, the performance of TD explicit learning group was upper than the DS implicit learning group during SRT task. The reason for this result is probably the explanation of sequence components in the explicit group of learners. Because the process of motor sequence learning consists of two parts; one of them is to learn the order of the elements and components in the sequences and the other is the ability to perform sequences. Therefore, explicit information about the sequences and sequences of the task can increase the accuracy and speed of learning and play a significant role in improving performance and motor skills. This result is consistent with Atwell, Conners \& Merrill, 2003; Salehi, Sheikh, Hemayattalab \& Humaneyan, 2016. Because in their research, explicit learning groups have had better performance than implicit learning groups.

In particular, our study involved reaction and coordination of index finger of the right hand. An interesting observation made while testing the some children in all groups is that when asked to move index finger in response to the visual stimulus, at times, they sometimes appeared to produce simultaneous motion in neighboring fingers. The children in TD and DS groups also required more familiarization trials before beginning the task, in order to learn the association between their index finger and the stimulus locations. Previous studies have shown that involuntary movements and poor performance of hand movements are normal features in young children (Wolf, Gunnoe \& Cohen, 1983; Garvey, Ziemann, Bartko, Denckla, Barker \& Wassermann, 2003). This issue, in the present study was particularly relevant for children with Down syndrome. A recent study that examined the cortical correlates of neuro-motor development in healthy children has shown that as children got older (i.e., 10-years-old), their finger speeds got faster and they exhibited less mirror movements (Garvey, Ziemann, Bartko, Denckla, Barker \& Wassermann, 2003), indicating better motor control. It was suggested that this developmental change in motor control parallels the maturational changes observed in the motor cortex and the cortico -spinal tract. Surprisingly, to our knowledge, there are numerous studies on fine motor control abilities in adults, such as determining the nature of interdependency between fingers during force production tasks (Lang and Schieber 2004; Reilly and Hammond, 2006), but relatively little is known about developmental changes in these fine motor control abilities in children. Especially children with learning difficulties and mental disorders (e.g., autism spectrum, developmental coordination disorder, down syndrome, etc.) Thus, future studies could explore this phenomenon thoroughly in all different childrenin in order to better understand the relationship between motor performance and motor control across development.

In summary, we can suggest that implicit motor learning is intact in children with DS and this fact is supported by some studies (Atwell, Conners \& Merrill., 2003; Vinter \& Detable, 2008). Our results to some extent differ from study done by Vinter \& Detable, 2008 mainly due to task features, task demands and the decreased possibility of using explicit strategies during implicit motor learning. Moreover, explicit motor learning seems to be impaired in children with DS. Nevertheless, this requires more empirical research. From a practical point of view, it can be mentioned that children with DS should be instructed for the targeted motor task and then be allowed to investigate it themselves without any more explanations about the steps of the task. In other words, during the physical education and rehabilitation interventions to children with DS, the physical practitioners and therapists can use the benefits of implicit learning, because based on the results of this study, these children can learn skills implicitly. 
Salehi, S. K.; Talebrokni, F. S.; Miri-Lavasani, N., \& Hajipour, A. (2018). Explicit and implicit motor sequence learning: motor learning analysis in children with Down syndrome. RICYDE. Revista internacional de ciencias del deporte. 57(15), 266-279. https://doi.org/10.5232/ricyde2019.05705

\section{Conclusion}

To conclude, the results of this experiment on sequence learning with the SRT task suggest that the capacity for explicit motor learning was reduced in individuals with DS compared to their controls. However, implicit motor sequence learning is preserved in DS children and not affected in these children but this kind of learning is not superior to explicit learning in this group. These results are just the beginning of a study on implicit learning in DS children. Further research is needed to provide more meticulous and logical explanations.

\section{Acknowledgments}

We are thankful to all the rehabilitation authorities, families for help and assistance and children for their participation in this study. We also wish to thank Abalfaz Alavi and Hossain Zaheri for their assistance and providing useful and beneficial suggestions.

\section{References}

Atwell, J. A.; Conners, F. A., \& Merrill, E. C (2003). Implicit and explicit learning in young adults with mental retardation. American Journal on Mental Retardation, 108(1), 5668. https://doi.org/10.1080/17470210903536910

Bittles, A. H.; Bower, C.; Hussain, R., \& Glasson, EJ (2007). The four ages of Down syndrome. European Journal of Public Health, 17(2), 221-5. https://doi.org/10.1093/eurpub/ckl103

Brown, J.; Aczel. B., Jiménez, L.; Kaufman, S. B., \& Grant, K. P. (2010). Intact implicit learning in autism spectrum conditions. The Quarterly Journal of Experimental Psychology, 63(9), 1789-812.

https://doi.org/10.1080/17470210903536910

Bussy. G.; Charrin. E.; Brun, A.; Curie, A., \& des Portes, V. (2011). Implicit procedural learning in fragile $X$ and Down syndrome. Journal of Intellectual Disability Research, 55(5), 521-8.

https://doi.org/10.1111/j.1365-2788.2011.01410.x

Chiviacowsky, C.; Machado, C.; Marques, A. C.; Schild J. F. G., \& Drews R. (2013). Motor learning and Down syndrome: effects of reduced relative frequency of knowledge of results. Revista Brasileira de Cineantropometria \& Desempenho Humano, 15, 225-232.

Cuskelly, M.; Jobling, A., \& Buckley, S. (Eds.). (2002). Down syndrome across the life span. Philadelphia, PA: Whur Publishers.

Deborah, J.; Fidler, L., \& Nadel, N. (2007). Education and Children with Down syndrome: Neuroscience, Development, and intervention. Mental retardation and developmental disabilities. Research reviews, 13(3), 262-271.

https://doi.org/10.1002/mrdd.20166

Dienes, Z.; Broadbent, D. E., \& Berry, D. C. (1991). Implicit and explicit knowledge bases in artificial grammar learning. Journal of Experimental Psychology: Learning, Memory, and Cognition, 17(5), 875-887.

https://doi.org/10.1037/0278-7393.17.5.875

Dulany, D. E.; Carlson, R. A., \& Dewey, G. I. (1984). A case of syntactical learning and judgment: How conscious and how abstract? Journal of Experimental Psychology: General, 113(4), 541-555.

https://doi.org/10.1037/0096-3445.113.4.541

Eichenbaum, H.; Matthew, P., \& Cohen, N. J. (1989). Further studies of hippocampal representation during odor discrimination learning. Behavioral Neuroscience, 103(6), 1207-1216.

https://doi.org/10.1037/0735-7044.103.6.1207 
Salehi, S. K.; Talebrokni, F. S.; Miri-Lavasani, N., \& Hajipour, A. (2018). Explicit and implicit motor sequence learning: motor learning analysis in children with Down syndrome. RICYDE. Revista internacional de ciencias del deporte. 57(15), 266-279. https://doi.org/10.5232/ricyde2019.05705

Fletcher, J.; Maybery, M.T., \& Bennett, S. (2000). Implicit learning differences: A question of developmental level? Journal of Experimental Psychology: Learning, Memory and Cognition, 26(1), 246-252.

https://doi.org/10.1037/0278-7393.26.1.246

Fowler, A. (1995). Linguistic variability in persons with Down syndrome: Research and implications. In L. Nadel \& D. Rosenthal (Eds.). Down syndrome: Living and learning in the community (121-131). New York: Wiley- Liss.

Gabriel, A.; Stefaniak, N.; Maillart, C.; Schmitz, X., \& Meulemans, T. (2012). Procedural visual learning in children with specific language impairment. American Journal of Speech-Language Pathology, 21(4), 329-341.

https://doi.org/10.1044/1058-0360(2012/11-0044)

Garvey, M.; Ziemann, U.; Bartko, J.; Denckla, M.; Barker, C., \& Wassermann, E. (2003). Cortical correlates of neuromotor development in healthy children. Clinical Neurophysiology. 114(9), 1662-1670. https://doi.org/10.1016/S1388-2457(03)00130-5

Gentile, A. M. (1998). Movement science: Implicit and explicit processing during acquisition of functional skills. Scandinavian Journal of Occupational Therapy, 5(1), 7-16. https://doi.org/10.3109/11038129809035723

Hick, R. F.; Botting, N., \& Conti-Ramsden, G. (2005). Short-term memory and vocabulary development in children with Down syndrome and children with specific language impairment. Developmental Medicine and Child Neurology, 47(8), 532-538. https://doi.org/10.1017/S0012162205001040

Izadi-Najafabadi, S.; Mirzakhani-Araghi, N.; Miri-Lavasani, N.; Nejati, V., \& PashazadehAzari, Z. (2015). Implicit and explicit motor learning: Application to children with Autism Spectrum Disorder (ASD). Research in Developmental Disabilities, 47(December), 284-296.

https://doi.org/10.1016/j.ridd.2015.09.020

Janacsek, K. J.; Fiser, D., \& Nemeth, D. (2012). The Best Time to Acquire New Skills: Age-related Differences in Implicit Sequence Learning across Human Life Span. Developmental Science, 15(4), 496-505. https://doi.org/10.1111/j.1467-7687.2012.01150.x

Karatekin, C.; Marcus, D. J., \& White, T. (2007). Oculomotor and manual indexes of incidental and intentional spatial sequence learning during middle childhood and adolescence. Journal of Experimental Child Psychology, 96(2), 107-130. https://doi.org/10.1016/j.jecp.2006.05.005

Kirkham, N.; Slemmer, J.; Richardson, D., \& Johnson, S. (2007). Location, location, location: Development of spatiotemporal sequence learning in infancy. Child Development, 78(5), 1559-1571.

https://doi.org/10.1111/j.1467-8624.2007.01083.x

Klinger, L., \& Dawson, G. (2001). Prototype formation in autism. Development and Psychopathology, 13(1), 111-124.

https://doi.org/10.1017/S0954579401001080

Lang, C., \& Schieber, M. (2004). Human finger independence: limitations due to passive mechanical coupling versus active neuromuscular control. Journal of Neurophysiology. 92(5), 2802-2810.

https://doi.org/10.1152/jn.00480.2004

Lejeune, C.; Catale, C.; Willems, S., \& Meulemans. T. (2013). Intact procedural motor sequence learning in developmental coordination disorder. Research in Developmental Disabilities, 34(6), 1974-1981.

https://doi.org/10.1016/j.ridd.2013.03.017 
Salehi, S. K.; Talebrokni, F. S.; Miri-Lavasani, N., \& Hajipour, A. (2018). Explicit and implicit motor sequence learning: motor learning analysis in children with Down syndrome. RICYDE. Revista internacional de ciencias del deporte. 57(15), 266-279. https://doi.org/10.5232/ricyde2019.05705

Maas, E.; Robin, D. A.; Hula, S. N. A.; Freedman, S. E.; Wulf, G; Ballard, K. J., \& Schmidt, R. A. (2008). Principles of Motor Learning in Treatment of Motor Speech Disorders, American Journal of Speech-Language Pathology, 17(3), 277-98. https://doi.org/10.1044/1058-0360(2008/025)

Maybery, M.; Taylor, M., \& O'Brien-Malone, A. (1995). Implicit learning: Sensitive to age but not to IQ. Australian Journal of Psychology, 47(1), 8-17. https://doi.org/10.1080/00049539508258763

Meulemans, T.; Van der Linden, M., \& Perruchet, P. (1998). Implicit sequence learning in children. Journal of Experimental Child Psychology, 69(3), 199-221. https://doi.org/10.1006/jecp.1998.2442

National Down syndrome Society. (2017). Down syndrome fact sheet. http://www.ndss.org/

Nejati V.; Garusi Farshi M. T.; Ashayeri H., \& Aghdasi M. T. (2008). Dual task interference in youth and elderly in explicit and implicit sequence learning. International Journal of Geriatric Psychiatry, 23(8), 801-804. https://doi.org/10.1002/gps.1976

Nissen, M. J., \& Bullemer, P. (1987). Attentional requirements of learning: Evidence from performance measures. Cognitive Psychology, 19(1), 1-32.

Oldfield, R. (1971). The assessment and analysis of handedness: The Edinburgh inventory. Neuropsychologia, 9(1), 97-113. https://doi.org/10.1016/0028-3932(71)90067-4

Perruchet, P, \& Vinter, A. (2002). The self-organizing consciousness. Behavioral and Brain Sciences, 25(3), 297-330. https://doi.org/10.1017/S0140525X02000067

Rast, M., \& Meltzoff, A. (1995). Memory and representation in young children with Down syndrome: Exploring deferred imitation and object permanence. Development and Psychopathology, 7(3), 393-407. https://doi.org/10.1017/S0954579400006593

Raven, J. C., Court, J. H., \& Raven, J. (1990). Manual for Raven's Coloured Progressive Matrices. Oxford: Oxfords Psychologists Press. https://doi.org/10.1037/02787393.2.1.88

Reber, A. S. (1976). Implicit learning of synthetic languages: The role of instructional set. Journal of Experimental Psychology: Learning, Memory and Cognition, 2, 88-94.

Reber, A. S. (1993). Implicit learning and tacit knowledge: An essay on the cognitive unconscious. New York: Oxford University Press. https://doi.org/10.1037/0278-7393.17.5.888

Reber, A. S.; Walkenfeld, F.F., \& Hernstadt, R. (1991). Implicit and explicit learning: Individual differences and IQ. Journal of Experimental Psychology: Learning, Memory, and Cognition, 17(5), 888.

https://doi.org/10.1037/0278-7393.17.5.888

Reilly K., Hammond G. (2006). Intrinsic hand muscles and digit independence on the preferred and non-preferred hands of humans. Experimental Brain Research. 173(4), 564-571. https://doi.org/10.1007/s00221-006-0397-7

Robertson, E. M. (2007). The serial reaction time task: Implicit motor skill learning? Journal of Neuroscience, 27(38), 10073-10075.

https://doi.org/10.1523/JNEUROSCI.2747-07.2007 
Salehi, S. K.; Talebrokni, F. S.; Miri-Lavasani, N., \& Hajipour, A. (2018). Explicit and implicit motor sequence learning: motor learning analysis in children with Down syndrome. RICYDE. Revista internacional de ciencias del deporte. 57(15), 266-279. https://doi.org/10.5232/ricyde2019.05705

Roizen, N. J., Patterson, D. (2003). Down's syndrome. Lancet (Review), 361(9365), 128189. https://doi.org/10.1016/S0140-6736(03)12987-X

Salehi, S. K.; Sheikh, M.; Hemayattalab, R., \& Humaneyan, D. (2016). The Effect of Different Ages levels and explicit - implicit Knowledge on Motor Sequence Learning. International Journal of Environmental and Science Education, 11(18), 13157-65.

Schacter, D. L. (1992). Understanding implicit memory: A cognitive neuroscience approach. American Psychologist, 47(4), 559-569. https://doi.org/10.1037/0003-066X.47.4.559

Sweeney, J. A.; Rosano, C.; Berman, R. A., \& Luna, B. (2001). Inhibitory control of attention declines more than working memory during normal aging. Neurobiology of Aging, 22(1), 39-47. https://doi.org/10.1016/S0197-4580(00)00175-5

Taylor, J. A., \& Ivry, R.B. (2013). Implicit and explicit processes in motor learning. In P.W.M. Beisert A, Herwig (Eds.), Action science (pp. 63-87). Cambridge, MA: The MIT Press. https://doi.org/10.7551/mitpress/9780262018555.003.0003

Thomas K.; Hunt; Vizueta N.; Sommer T.; Durston S., Yang Y., \& Worden M. (2004). Evidence of developmental differences in implicit sequence learning: an fMRI study of children and adults. Journal of Cognitive Neuroscience, 16(8), 1339-1351. https://doi.org/10.1162/0898929042304688

Thomas, K. M., \& Nelson, C. A. (2001). Serial reaction time learning in preschool and school-age children. Journal of Experimental Psychology, 79, 364-387.

Tulving, E., \& Schacter, D. L. (1990). Priming and human memory systems. Science, 247(4949), 301-306.

https://doi.org/10.1126/science.2296719

Vicari, S. (2006). Motor development and neuropsychological patterns in persons with Down syndrome. Behavior Genetics, 36, 355-364.

Vicari, S.; Bellucci, S., \& Carlesimo, G. A. (2000). Implicit and explicit memory: A functional dissociation in persons with Down syndrome. Neuropsychologia, 38(3), 240251. https://doi.org/10.1016/S0028-3932(99)00081-0

Vicari, S.; Verucci, L., Carlesimo, G. A. (2007). Implicit memory is independent from IQ and age but not from etiology: evidence from Down and Williams syndromes. Journal of Intellectual Disability Research, 51(12), 932-41. https://doi.org/10.1111/j.1365-2788.2007.01003.x

Vinter, A. \& Detable, C. (2008). Implicit and explicit motor learning in children with and without Down's syndrome. British Journal of Developmental Psychology. 26(4), 507523. https://doi.org/10.1348/026151007X267300

Weeks, D. J.; Chua, R., \& Elliott, D. (2000). Perceptual - motor behavior in Down syndrome. Champaign, IL: Human Kinetics.

Wolf, P.; Gunnoe, C., \& Cohen, C. (1983). Associated movements as a measure of developmental age. Developmental Medicine \& Child Neurology. 25(4), 417-429. https://doi.org/10.1111/j.1469-8749.1983.tb13786.x

Wright, I.; Lewis, V., \& Collis, G. M. (2006). Imitation and representational development in young children with Down syndrome. British Journal of Developmental Psychology, 24(2), 429-450.

https://doi.org/10.1348/026151005X51257 